\title{
Comprehensive Education or Vocational Training for the Unemployed?
}

\author{
Anders Stenberg*
}

\begin{abstract}
The Adult Education Initiative (AEI) in Sweden was introduced in the autumn of 1997 and generated a massive expansion of subsidized adult comprehensive education. This paper uses data on a large sample of individuals, aged 25 to 55 and unemployed in 1997, to evaluate the effects of comprehensive upper secondary education as compared with the vocational part of Labour Market Training (LMT). Register data of annual wage earnings are available from 1991 to 2003. Fixed effects estimates indicate a weaker impact on wage earnings of comprehensive education relative to vocational training. However, for individuals aged 4355 the parameters are insignificantly different from zero. Coefficient results close to zero are also obtained for females who prior to enrolment had two-year upper secondary school or resided in a municipality associated with a low average educational level.
\end{abstract}

Keywords: Adult education, wage earnings

JEL classification: J68, H52

* Author's address: SOFI, Stockholm University, SE-106 91 Stockholm, Sweden. Fax: +468154670. E-mail: anders.stenberg@sofi.su.se. I wish to thank Roger Axelsson, Niklas Hanes, Per Johansson, Mikael Lindahl, Olle Westerlund, Magnus Wikström as well as seminar participants at IFAU, Uppsala. Financial support from The Commission for Adult Education and Training is gratefully acknowledged. All errors of fact or judgment are my own. 


\section{Introduction}

In recent decades, comprehensive education for adults has become an increasingly important policy tool in many OECD-countries. Explanations for this development are an increasing gap in employment rates between people of high and low education, a strong belief in the growth-enhancement powers of human capital investment, and the fact that an ageing population has meant that human capital adjustments are made within the existing work force rather than through an inflow of workers with new skills. Yet, in spite of the considerable public and private investments in adult comprehensive education over many years, little is known about its economic benefits. Few evaluations have been made of adult comprehensive education, and no more than a small part of these focus on the effects for the unemployed.

The purpose of this study is to evaluate the effects of comprehensive education as compared with vocational training by using Swedish data on a large sample of unemployed individuals. A study of the relative average returns to general and specific human capital accumulation is highly relevant because of its potentially important implications for the design of active labour market policy. Moreover, adult comprehensive education is a straightforward measure that is easy to implement in many countries. The participants in the comprehensive education program described in this paper were enrolled in the Adult Education Initiative (AEI, Kunskapslyftet), which from the autumn of 1997 generated a massive expansion of heavily subsidized adult comprehensive education. The vocational program participants were enrolled in Labour Market Training (LMT, Arbetsmarknadsutbildning). The active nature of the Swedish labor market policies in the 1990's makes it inappropriate to use "non-participants" as comparison group since individuals in continued unemployment tend either to participate in other programs or to find employment. The choice of vocational training as reference group is of interest as it is a type of program that exists in most countries. Also, vocational LMT was a large program with target groups similar to those of the AEI. If the AEI had not existed, LMT would have been the alternative for many individuals.

The AEI offered the unemployed aged 25-55 a year of full-time comprehensive education at upper secondary level with financial support in the form of a special grant for education and training, UBS, which corresponded to their unemploy- 
ment insurance (UI) benefits. ${ }^{1}$ Apart from the unemployed, the AEI was also offered to individuals in employment with a short education, on the condition that their employer agreed to hire a person in long-term unemployment as their replacement. The AEI courses were mainly carried out at municipal adult education centres, komvux, an established institution within the Swedish educational system since the early 1970 's. To meet this greater demand for adult education, the municipalities received financial support from the government. Enrolees in the AEI and participants in regular komvux would usually share the same class-room. Courses at komvux typically last a semester, i.e. in the autumn from August to December and/or in the spring from January until the start of June.

The labour market situation preceding the large-scale AEI investment is partly illustrated by Figure 1 below. At the start of the 1990's, an economic recession hit Sweden. Between 1990 and 1993 unemployment rates soared from 1.7 to 8.2 per cent of the total labour force. The policy response was to increase the share in active labour market programs. In 1992, the participants in LMT, the largest program, represented 2.0 per cent of the labour force. However, open unemployment remained high, giving rise to growing concern regarding the marginal returns on traditional labour market measures. As customary, a high proportion of the unemployed had a low level of education, and their relative labour market position had also been weakened by a school reform, fully implemented from 1995-96, which extended the two-year upper secondary programs to three years in order to meet the standards of eligibility for higher education.

The circumstances provided arguments in favour of additional public expenditure on adult education. A year of full-time studies at komvux offered an alternative to the existing traditional labour market programs and also a way of bridging the educational gap for those with only a two-year upper secondary diploma from the previous system of education. More conventional arguments held that subsidized education would enhance economic growth, reduce unemployment and serve as an encouragement for further studies.

\footnotetext{
${ }^{1}$ The UI benefit level was based on wage earnings before unemployment and required previous membership in a UI-fund for at least 12 months, and at least part-time work for a minimum of six of those months.
} 
Figure 1. Percentages of the total labour force in unemployment, labour market programs and adult education in Sweden 1990 - 2002.

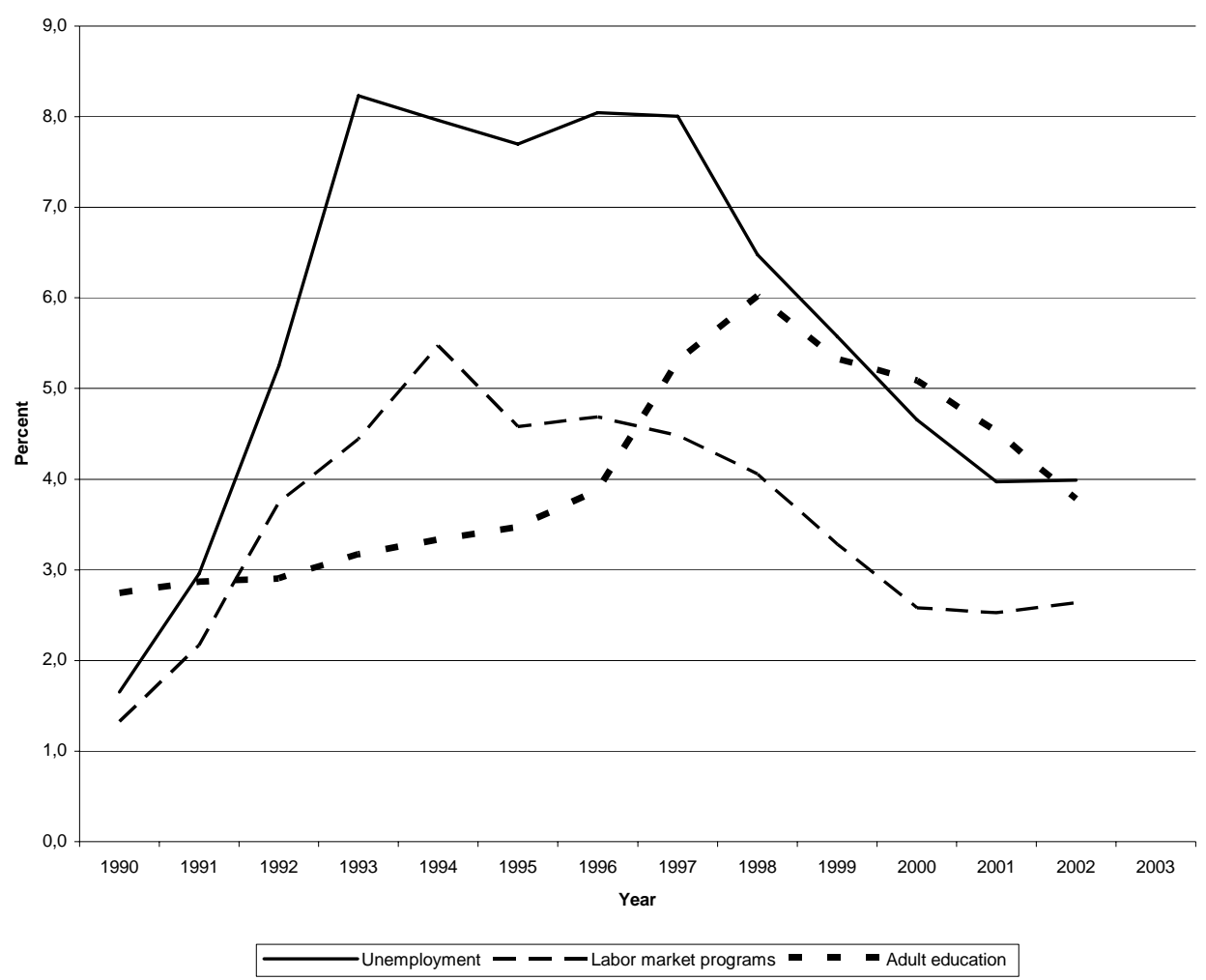

Note: 'Adult education' denotes the number of individuals enrolled in at least one course during a calendar year. This includes a large fraction attending only short courses. Unemployment and labour market programs are measured as yearly averages.

The AEI was introduced in the autumn of 1997 and the persons enrolled immediately represented 1.2 per cent of the total labour force. The numbers exceeded those in LMT, which since the 1950's had been the largest labour market program in Sweden. The policy declarations of the two programs made a priority of supporting individuals with a weak position in the labour market. The training grant of both programs equalled regular UI benefits and completing a course lasting more than six months also qualified for a new period of 300 days of benefits. Each individual's choice of program was made in consultation with a case worker at an employment office. If the individuals fulfilled the formal criteria, aged 25-55 and eligible to UI benefits, they were normally entitled to attend their program of preference.

The various types of vocational training offered in LMT focused on sectors where there were shortages of labour supply. About a third of those in LMT were in 
"preparatory training" which included courses in job-seeking or preparation for other programs. However, the LMT referred to in this paper only concerns the vocational training part of the program, so that individuals in preparatory training are excluded.

There have been many evaluations of LMT in Sweden. An interesting point of departure is Andrén and Gustafsson (2005) who find LMT participants during the 1980 's to have experienced a positive pay-off while those enrolled at the start of the 1990's had a negative program effect. Overall, studies of LMT with data collected at the start of the 1990's tend to report negative or negligible effects (Harkman et al. 1996, Larsson 2000, Regnér 2002, Richardson and van den Berg 2002 and Sianesi 2001). Presumably, the economic fluctuations displayed in Figure 1 partly explain these findings. At that time, LMT was the only program that qualified the individual for a new period of unemployment benefits, creating nonproductive incentives to participate. From 1994 this condition changed to incorporate relief works. Okeke (2001) used data on LMT participants in 1998 and finds positive effects on the probability of being employed six months after program completion compared with a matched sample. Stenberg and Westerlund (2004), studying long-term unemployed persons in 1997, find strong evidence of a positive impact of LMT on annual wage earnings. Axelsson and Westerlund (2005) similarly find a significant positive pay-off on wage earnings for participants in LMT in 1997.

The economic literature on formal education for adults is rather limited. A study from the US is Leigh and Gill (1997) who analyse the impact of community college on log wages for individuals aged 25 to 35 . They find positive effects that do not differ from those of the younger students (Grubb, 2002, provides an extensive survey of US studies). Studies with data from the UK include Jenkins et al. (2003) who, with only minor exceptions, find no evidence of a positive impact of mid-career education on wages or employment. Egerton and Parry (2001) find the rate of return for mature graduates in full-time employment to be just above one per cent for males and five per cent for females, but that wage gains from a degree are smaller for older compared with younger graduates. Ekström (2003) studied Swedish data on participants at upper secondary level komvux from 1989 to 1993. Annual wage earnings in 2000 are used as outcomes and the results indicate negative returns for Swedish-born men but positive returns for female immigrants. From analyzing subgroups, the negative returns for men are found to be in the region of 3 per cent for those aged 25-42 and around 6 per cent for men aged 43-55. 
Studies that examine the impact of comprehensive education on samples of unemployed include Jacobson et al. (2005), who use panel data on laid-off workers in Washington State. Many of the laid-off workers attended community college courses that ranged from basic skills and vocational training to academic courses in mathematics and science. They report average increases in earnings in the neighbourhood of 10 per cent, slightly lower for males and slightly higher for females, but also that the returns were up to three times higher for technically oriented courses. For the UK, Jenkins (2004), using data on females out of work in 1991, finds a strong positive relationship between adult education that led to a qualification and a return to employment in 2000.

Albrecht et al. (2004) studied the effects of the AEI on the changes in wage earnings between 1994 and 2000. Their analysis is based on a random sample of 200,000 individuals from the Swedish population, trimmed according to six criteria. They thereby created a rather small sample of treated individuals where each of their subgroups consists of less than 100 observations. The results indicate no significant effects on wage earnings, but a higher probability for men aged 25-40 to find employment compared with the control group. ${ }^{2}$ Stenberg (2005) uses a sample enrolled in the AEI in the autumn of 1997 to compare the impacts of comprehensive education and vocational LMT on unemployment incidence and unemployment duration. Comprehensive education is linked to a lower probability of unemployment incidence following program, but given unemployment, LMT is found to have more beneficial effects on unemployment duration. A problem with the outcome variables is that no distinction is made between part-time and fulltime unemployment. In addition, those "not in unemployment" could be in such dissimilar activities as employment or withdrawn from the labour market.

The contribution of this paper is to use a large sample of unemployed to evaluate the effects on annual gross wage earnings of comprehensive education at upper secondary level relative to vocational training. The wage earnings include gross salary and holiday compensation but not taxable benefits or transfers such as UI. Wage earnings data are available from 1991 to 2003, providing observations from both before and after program. General equilibrium effects caused by these programs are not considered in this study. For a simulation study of equilibrium effects of the AEI, see Albrecht et al. (2004).

\footnotetext{
${ }^{2}$ Their criteria to identify the treated group do not include the special grant, UBS, or records of unemployment. This actually means that there is no distinction made between regular komvux and the AEI.
} 
The plan of the paper is to first describe the data. Section three presents the estimation results and section four contains a concluding summary.

\section{The data}

This study is based on register data originating from the total population register, the register of adult education (komvuxdatabasen), and the event history database (Händel) of the National Swedish Labour Market Board (AMS). Händel contains daily records of all individuals in search of work at any employment office in Sweden. Individuals are classified into different categories depending on whether they are openly unemployed or participating in some labour market program, for example LMT. Participants in the AEI are not included in the Händel data set but instead are collected from the register of adult education which includes all individuals participating in komvux.

The data collected consists of

1. the stock registered in Händel as participating in LMT on October 15, 1997.

2. the individuals aged 25-55 registered in adult education at komvux at some time during the autumn semester of 1997.

To distinguish the participants in the AEI from individuals in regular adult education, information is used on whether the individuals received the special grant for education and training, UBS. It was equal to UI benefits and a part of the government funding of the AEI. Eligibility requirements for the UBS were: age 25-55, enrolment in studies at elementary or upper secondary level, and entitlement to UI when the studies were initiated. If the individual was employed, his or her employer must have agreed to hire a long-term unemployed person as a replacement. Individuals with a completed three-year upper secondary education could also be considered on various grounds. ${ }^{3}$ Participants in the AEI are here defined as those who were registered in upper secondary adult education at some point during the autumn of 1997 and who received the special grant UBS during the same semester. This applied to 43,058 individuals. Those enrolled in the AEI in 1997 were offered an extension of UBS to include another year from the autumn of 1998,

\footnotetext{
${ }^{3}$ If the individual lacked grades or sufficient knowledge in one or more subjects, had had a particularly long unemployment period, or had an 'old' secondary school diploma. Some briefer college educations were also considered as "incomplete upper secondary school".
} 
something which 20,735 individuals accepted. AEI studies consisted of the compulsory subjects mathematics, Swedish, social science and English. Besides these were other theoretical subjects, and according to aggregate data in the Report of the Government Commission (SOU 1998:51), 24 per cent also attended vocational courses. Information on the specific courses taken by the enrolees is not available.

The vocational part of LMT included 21,867 individuals in 1997. Offering a wide range of training programs, LMT was considerably more heterogeneous in scope compared with the AEI. Also, while the AEI only started once a year at the beginning of the autumn semester, LMT program-starts were more dispersed with only around 60 per cent starting on August 15 or later. Again, there are no individual records of the specific courses attended within the program but the Swedish Labour Market Board, the public authority responsible for LMT, reports that the five largest sectors represented were technology and science, health care, administration, manufacturing and service (AMS 2000). The courses were purchased either by their regional offices or by local employment agencies from various educational organizations. Five per cent of the courses offered at LMT were purchased from komvux. So it is possible that small fractions of participants in the AEI and LMT attended the same courses.

As there are no individual drop-out records from either program, the interpretation of "participation" should be program started rather than program completed. The existing information on drop-out frequency is based on survey data. AMS (1999) reported that for the vocational training part of LMT, the drop-out rate in the second quarter of 1998 was approximately 18 per cent. Concerning the AEI, the Report of the Government Commission on Adult Education (SOU 1999:39) stated that 10 per cent had interrupted their studies. Both these figures include individuals that interrupted their program because they had found work.

In order to make the samples of program participants more comparable, individuals not fulfilling a number of criteria are excluded from the study. These criteria are discussed and motivated below. Note that in most cases, individuals are excluded as a consequence of more than one restriction.

- As mentioned, it was possible to enrol in the AEI from employment. To focus on those who enrolled from unemployment, individuals in the AEI are left out if they had zero days as registered job seekers during the year 
of enrolment ( 8,114 observations). The fraction excluded is 14.4 per cent, which is close to the 16.2 per cent reported as enrolled from employment in the Report of the Government Commission on Adult Education (SOU 1998:51).

- To make the age spans of the participants in LMT identical to the AEI, individuals not aged 25 to 55 are excluded (4,487 observations).

- Enrolment in the AEI took place from mid-August each year. To keep the timing of LMT relatively similar, individuals enrolled in LMT prior to May 1997 are excluded (4,775 observations).

- AEI participants who were registered in adult education in the spring semester of 1997 are excluded (11,126 observations). Presumably, these individuals would have continued their studies even without the introduction of the AEI.

- Individuals are excluded if they do not have at least one year from 1991 to 1996 with registered annual wage earnings above SEK 20,000 and at least one year above zero 2000-2003 (4,217 observations). As the logarithmic values of annual wage earnings are used as outcomes in the empirical section, low initial levels may turn the relative changes into absurdly high percentages.

Following these exclusions, 32,761 individuals remain, of which 69.2 per cent were enrolled in the AEI. The analysis from here on concerns these individuals unless otherwise stated.

Various pre-program characteristics of the chosen sample are displayed in Table 1. The first three dummy variables are related to regional residency in the year of enrolment. The distribution of financial support from the government to the municipalities was partly meant to level out regional differences. Participation in the AEI was therefore more common in municipalities associated with a low educational level. "High percentage of three-year secondary school diplomas" is a municipal dummy variable constructed to reflect a high local educational level. The value is one for individuals residing in municipalities where the fraction of the population with at least a three-year upper secondary education exceeds the median (among individuals) of the whole population. This applies to 67 out of the 288 municipalities, representing 54.4 per cent of the population (municipalities with high populations tend to have high fractions). The inland region of Norrland is a sparsely populated area in the north of Sweden made up of municipalities with no coastline and covering 49 per cent of the area of the country but contain- 
ing only 4.8 per cent of the population. This region has a permanently higher than average unemployment rate. Stockholm County, where 20 per cent of the population resides, is in many respects its opposite, as the diversity of branches and the overall employment level is higher than in any other region of Sweden.

Table 1 reveals further that the AEI participants were slightly younger, but that the foreign born and males were more attracted by LMT. Females represented 70.8 per cent of the AEI participants and 48.0 per cent of the LMT sample. The largest educational group in both programs were those with a two-year upper secondary school diploma. For the AEI, this proportion was particularly high, almost 66 per cent. This is as expected, since a year of comprehensive education would render a formal diploma of three-year upper secondary school and eligibility to higher education.

Overall, the educational levels of the AEI participants were more homogeneous compared with those in LMT. ${ }^{4}$ Note also that substantial fractions in both programs had zero wage earnings the year before program enrolment.

\footnotetext{
${ }^{4}$ In the groups with the highest and lowest educational levels, foreign citizens and older age groups were overrepresented. An exception to this rule is the no longer existing elementary level which concern very few foreign citizens. It was replaced stepwise by the nine year compulsory school between 1962 and 1972.
} 
Table 1: Descriptive averages in 1997 (unless otherwise stated) of participants in the AEI and LMT.

\begin{tabular}{|c|c|c|c|c|}
\hline \multirow[b]{3}{*}{$\begin{array}{l}\text { High \% with } 3 \text {-year secon- } \\
\text { dary school diploma }\end{array}$} & \multicolumn{2}{|c|}{ Males } & \multicolumn{2}{|c|}{ Females } \\
\hline & AEI & LMT & AEI & LMT \\
\hline & .476 & .512 & .401 & .507 \\
\hline Stockholm County & .136 & .124 & .112 & .145 \\
\hline Inland of Norrland & .092 & 092 & .077 & .069 \\
\hline Age & 35.8 & 37.5 & 35.8 & 37.9 \\
\hline Married & .261 & .301 & .378 & .369 \\
\hline Child $<16$ living at home & .217 & .225 & .659 & .547 \\
\hline Elementary school & .022 & .031 & .019 & .025 \\
\hline Compulsory school & .193 & .160 & .182 & .133 \\
\hline 2-year secondary school & .635 & .471 & .666 & .440 \\
\hline 3-year secondary school & .095 & .143 & .081 & .182 \\
\hline$<3$ years of university & .047 & .133 & .045 & .141 \\
\hline$\geq 3$ years of university & .009 & .063 & .008 & .079 \\
\hline Swedish citizen & .954 & .947 & .962 & .948 \\
\hline Foreign born & .116 & .145 & .095 & .117 \\
\hline Eligible for UI & .963 & .921 & .954 & .920 \\
\hline Working disability & .102 & .126 & .073 & .103 \\
\hline Zero wage earnings 1996 & .242 & .281 & .205 & .217 \\
\hline Wage earnings 1996 & 82,452 & 73,278 & 68,617 & 66,362 \\
\hline Total no. of observations: & 6,614 & 5,239 & 16,065 & 4,843 \\
\hline AEI 1 semester & 893 & & 1,933 & \\
\hline AEI 2 semesters & 2,706 & & 5,737 & \\
\hline AEI 3 semesters & 1,070 & & 2,970 & \\
\hline AEI 4 semesters & 1,945 & & 5,425 & \\
\hline
\end{tabular}

Figures 2 and 3 below display the annual wage earnings trajectories, expressed in 2003 values, of the participants in the AEI and LMT. ${ }^{5}$ It has often been observed that those who enrol in labour market programs have on average depressed earnings before enrolment but the pre-program annual wages display relatively modest decreases in 1996. The AEI participants had in general higher pre-program wage earnings compared with LMT. Participants in LMT had relatively short program durations so their post-program increases start earlier than for the AEI participants with more than one semester. The AEI groups recover one by one but only females with three semesters actually catch up with the level attained by LMT. Thus, from these descriptive data LMT looks like the more efficient policy tool.

\footnotetext{
${ }^{5}$ In 2003 the values of $€ 1$ was on average SEK 9.12.
} 
It should be noted that many individuals progressed from low levels of wage earnings. Those with annual earnings below SEK 50,000 in 1996 had a more than tenfold increase in their averages by 2003. The increase of the AEI participants was 1,070 per cent while those in LMT increased by 1,285 per cent. The individuals with annual earnings above SEK 50,000 in 1996 showed more moderate improvements, 20.9 per cent for the AEI and 26.5 per cent for the group in LMT.

Figure 2; Average annual wage earnings trajectories, males.

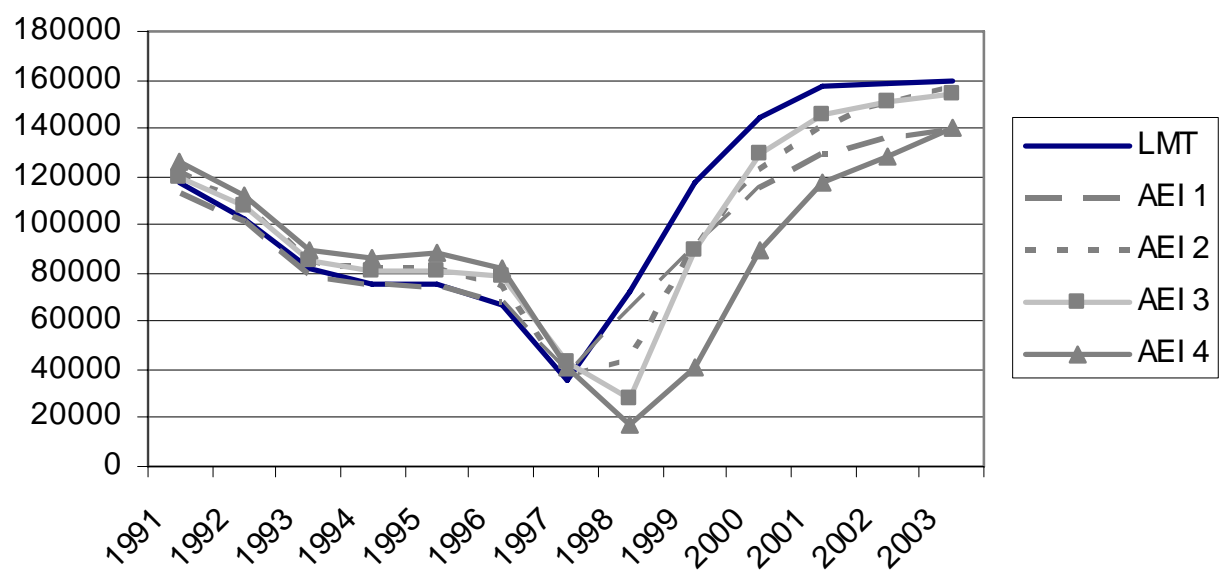

Figure 3; Average annual wage earnings trajectories, females.

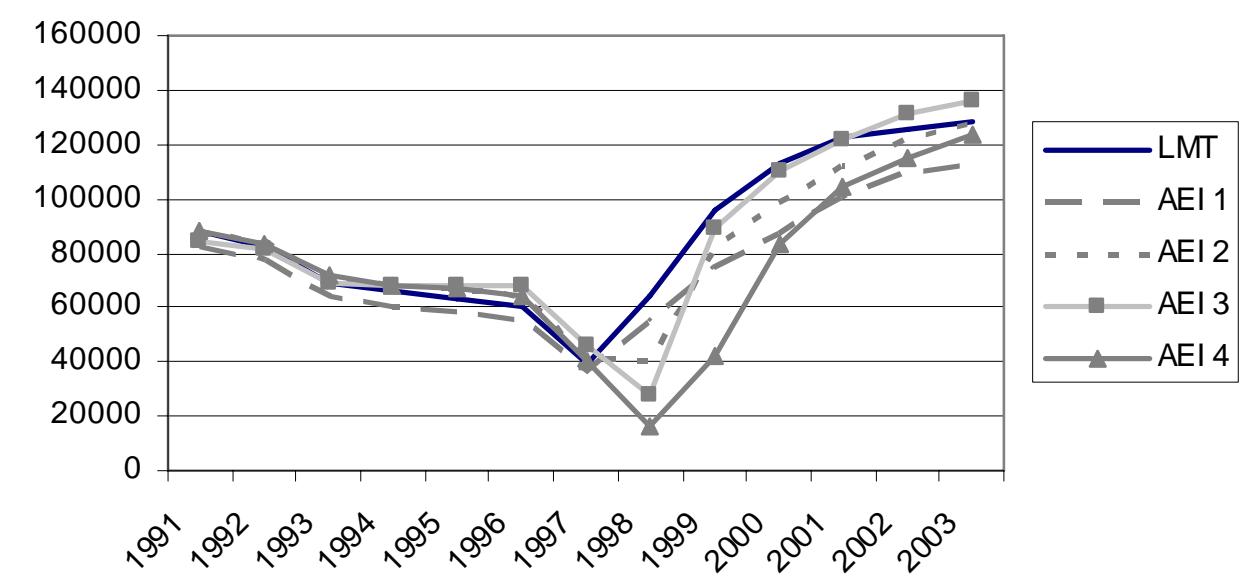




\section{Estimation results}

The evaluation problem as presented in the economics literature usually assumes a framework where individuals are in one of two states. The potential outcomes are $y_{1}$ for treatment (participation in the AEI) and $y_{0}$ for no treatment (in this study, another program, LMT). Hence, for each individual, there is a pair of outcomes of which only one can be observed. Most evaluation studies seek the average treatment effect on the treated, $E\left[y_{1}-y_{0} \mid D=1\right]$ where $D$ equals one for participation and zero for non-participation. In general, the focus is on comparing the outcomes of the participants with the outcomes of a sample of non-participants which then serve as an estimate of $E\left[y_{0} \mid D=1\right]$, i.e. what would have happened to the treated individuals had they not participated. The potential bias $b$ can be written as

$$
b=E\left[y_{0} \mid D=1\right]-E\left[y_{0} \mid D=0\right]
$$

Several econometric methods have been suggested to control for this bias. The approach adopted here is to take advantage of the information contained in the panel structure of the wage earnings data by using a fixed effects model. It assumes that the selection bias is due to time-invariant unobserved heterogeneity that affects wage earnings. More specifically, the linear regression model is of the form

$$
y_{i t}=\alpha+\mu_{i}+\theta_{t}+x_{i t} \beta+\gamma D_{i t}+\varepsilon_{i t}
$$

where the LHS variable $y_{i t}$ denotes annual wage earnings for individual $i$ at time $t$. This is a function of a constant, $\alpha$, individual-specific fixed effects, $\mu_{i}$, time-specific fixed effects, $\theta_{t}$, and time varying observable characteristics, $x_{i t}$, which are age squared and a dummy which takes the value one if the individual was registered in any of the programs in that particular year. The relative impact of program is reflected by $\gamma$ which is attached to a dummy $D_{i t}$ that indicates post-AEI wage earnings and $\varepsilon_{i t}$ is the residual term. The general AEI dummy $D_{i t}$ is used interchangeably with $d_{i t}$ which is specific to each group with one to four semesters $\left(D_{i t}=\sum_{i} d_{i t}\right)$.

In Tables 2 and 3 below, results are presented from fixed effects regressions on annual wage earnings of the male and the female samples. Estimates using both the absolute and the logarithmic values are reported. The estimation results in columns (1) to (4) are influenced by the fact that some individuals, most notably from the AEI, continued their studies at komvux or at university level. For this 
reason, the columns labelled (5) to (8) report results from samples which exclude all individuals that were registered in some form of education in 2001 or later. This reduces the samples by 22 per cent for males and by 30 per cent for females.

The main implication of the results in Tables 2 and 3 is that the AEI had significantly negative effects relative to LMT on post-program wage earnings. The female estimates are generally closer to zero and the parameters of those with three semesters are insignificantly different from zero in the female sample, implying that for this group the AEI had an impact equal to that of LMT. There is also a clear pattern, for both men and women, that those with four semesters display a weaker impact compared with three semesters. What this probably reflects is that individuals who had difficulties completing their courses were liable to remain in the AEI the maximum amount of time. It may also in part consist of individuals who used the AEI as a means to prolong their eligibility for the special grant, UBS.

When the restricted samples are used, in columns (5) to (8), the parameters are generally reduced towards zero. For males, the general estimates are reduced from a negative value of about 33 per cent to 22 per cent, and for females from approximately 12 per cent to 6 per cent. The reduction for the semester-specific dummies is particularly strong for the group with four semesters, which is almost halved for males and reduced by three quarters for females. However, it is not obvious what the differing results of the restricted and the unrestricted samples imply for a future evaluation with a longer time-frame. Some individuals probably selected to remain in classroom teaching because they could not find work, while others who continued in higher education may become future high earners. At any rate, the indirect locking-in effects of the AEI are obviously very influential on the estimates. This is partly a consequence of the relatively generous study allowances in Sweden, which are approximately $€ 700$ a month, of which one-third is a loan.

A possible interpretation of the results so far is that the AEI should have been scaled down, e.g. through the eligibility rules and/or a less generous training grant, to steer some participants to LMT rather than to the AEI. 
Table 2: Male sample fixed effects regression results of the impact of the AEI relative to LMT.

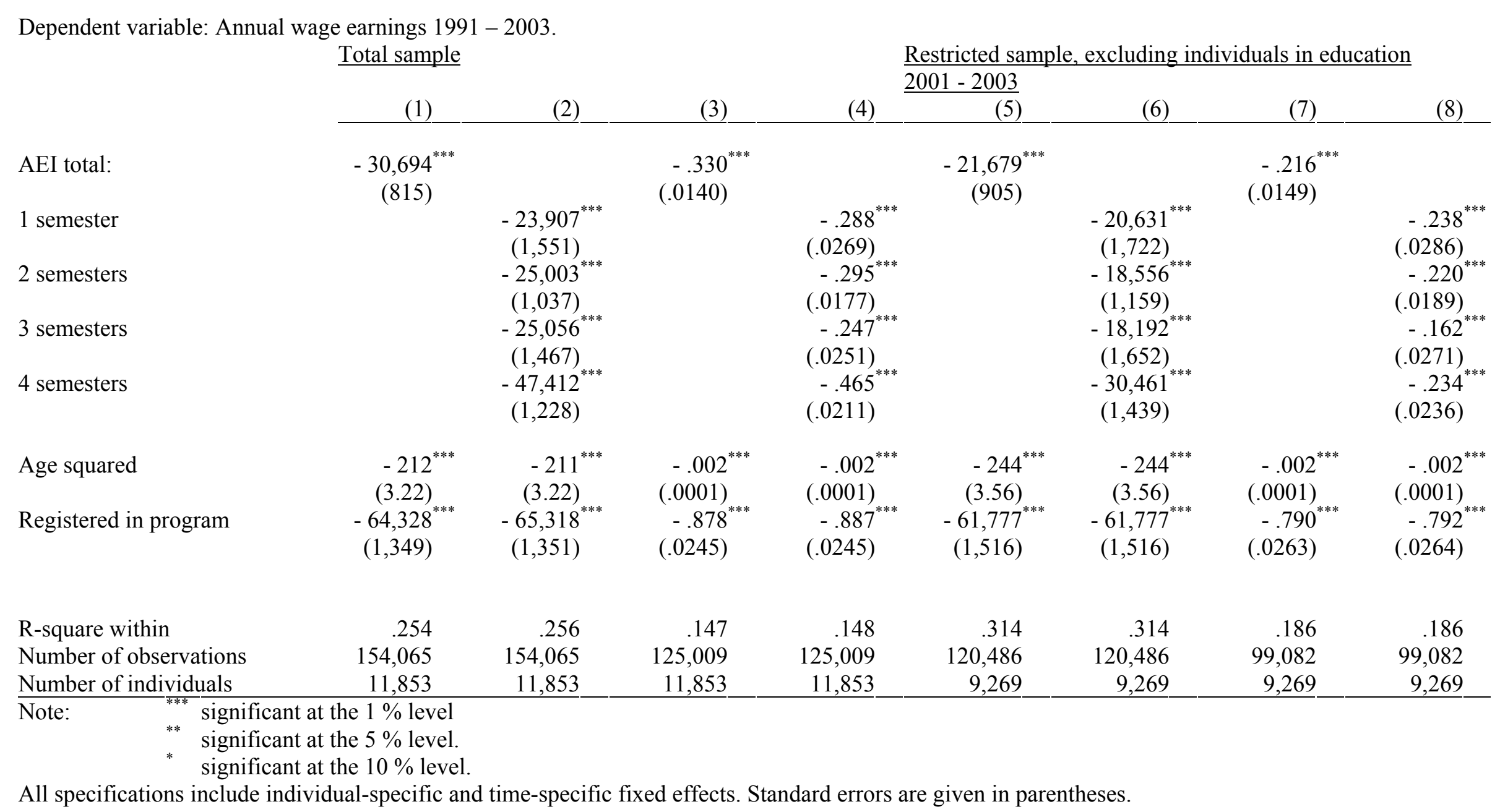


Table 3: Female sample fixed effects regression results of the impact of the AEI relative to LMT.

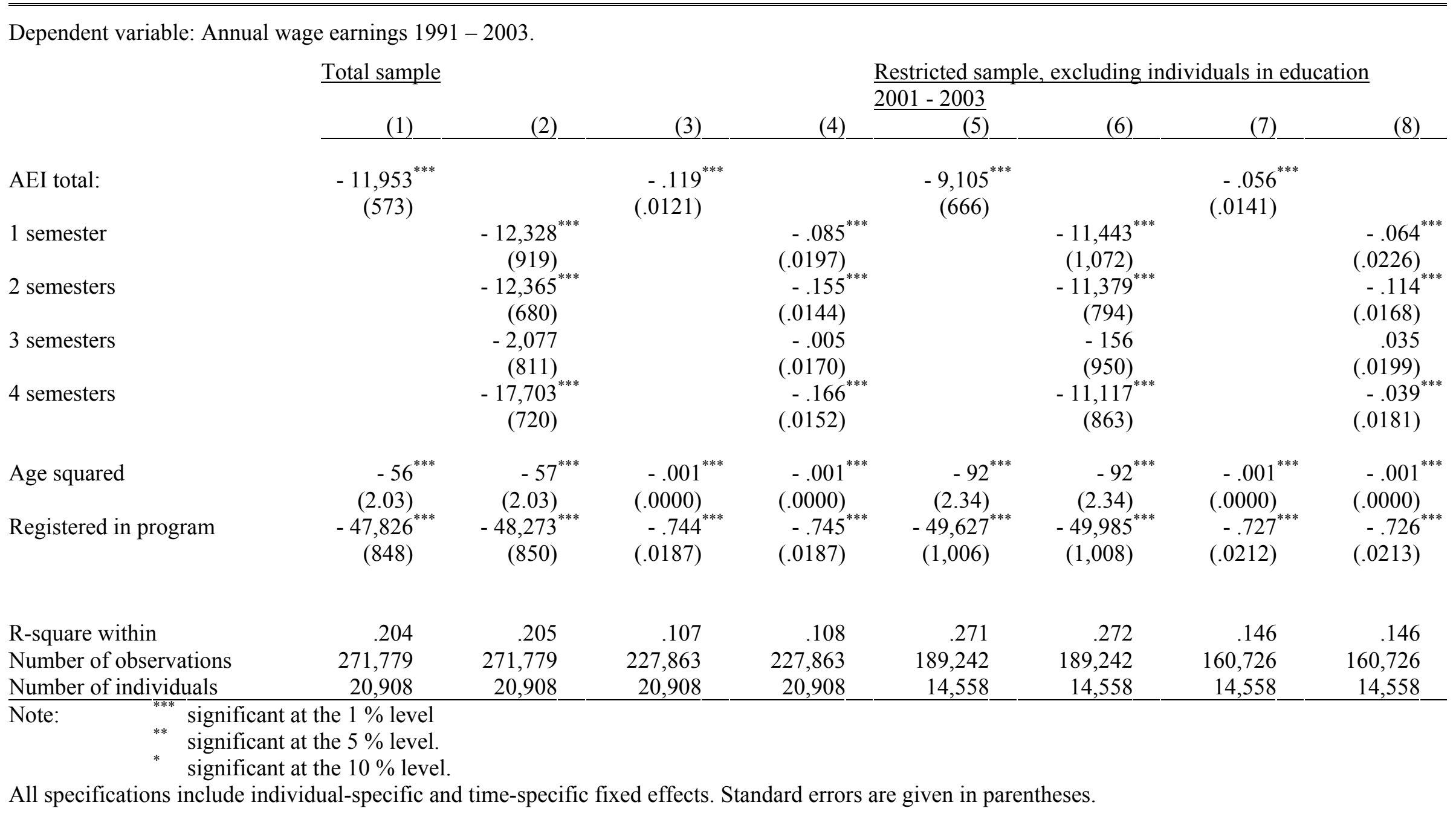


Table 4 and Table 5 present regression results from using various parts of the male and female samples. In Tables 6 and 7 these are repeated but with the further restriction of not having been registered in education from 2001 and onwards. The $\log$ of annual wage earnings is the dependent variable throughout. In the first four columns of each table, the samples are limited to those with a prior two-year upper secondary diploma (columns 1 and 2) and residents in municipalities associated with a low educational level (columns 3 and 4). These columns report very similar results. Compared with the negative effects observed earlier, the coefficients are marginally reduced for the male sample. In the case of females, the estimates are less than two thirds compared with Table 3 and when those in education from 2001 are excluded, most parameters are insignificantly different from zero (Table 7). In the last four columns of each table, the samples are divided in two parts, aged 25-42 and 43-55. The results obtained differ sharply between these age-groups. Compared with Tables 2 and 3, the coefficient values of the younger sample are higher in absolute terms. With the older sample, the parameters are mostly insignificant from zero, suggesting that general adult education was as efficient a measure as specific training.

On the whole, the results obtained suggest that more careful targeting of the participants in adult education could have improved the relative efficiency of the program. 
Table 4: Total male sample fixed effects regression results of the impact of the AEI relative to LMT, various samples.

Dependent variable: Log annual wage earnings 1991 - 2003.

$\begin{array}{ll}\text { Prior 2-year upper } & \begin{array}{l}\text { Municipality with low fraction } \\ \text { of 3-year upp sec diploma }\end{array}\end{array}$

Age 25-42 Age 43-55

AEI total:

$$
-.289^{* * *}
$$

$-.283^{* * *}$

$(.0196)$

$-.223^{* * *}$

$(.0343)$

semester

$-.254^{*}$

2 semesters

$(.0229)$
$-.197^{* * *}$

3 semesters

(.0313)

4 semesters

$$
{ }^{-.443^{* * *}}
$$

$-.251^{* * *}$
$(.0392)^{* *}$
$-.266^{* *}$
$(.0243)^{* *}$
$-.159^{* *}$
$(.0362)^{* *}$
$-.393^{* * *}$
$(.0287)$

$-.414^{* * *}$

(.0160)

$-.059^{* *}$

(.0287)

Age squared

$\begin{array}{ll}-.002^{* * *} & -.002^{* * *} \\ (.0001)^{* * *} & (.0001)^{* * *} \\ -.893^{* *} & -.902^{* * *} \\ (.0324) & (.0324)\end{array}$

$\begin{array}{ll}-.002^{* * *} & -.002^{* * *} \\ (.0001)^{* *} & (.0001)^{* * *} \\ -.825^{* * *} & -.825^{* * *} \\ (.0342) & (.0342)\end{array}$

$-.002^{* * *}$

$(.0001)$

$-.975^{* * *}$

$(.0280)$

$$
\begin{gathered}
-.405^{* * *} \\
(.0308)^{* * *} \\
-.370^{* *} \\
(.0200)^{* * *} \\
-.299^{* *} \\
(.0281)^{* * *} \\
-.567^{* *} \\
(.0237)
\end{gathered}
$$

$(.0556)$

$-.058$

$(.0382)$

$-.096^{*}$

(.0565)

$. .0565)^{* *}$
$-.109^{* *}$

(.0462)

Registered in program

$$
\text { (.0324) (.0324) }
$$

$(.0342)$

(.0342)
$-.002^{* * *}$
(.0001)
- .988
(.0281)

$-.003^{* * *}$

$-.003^{* * *}$

(.0002)

(.0002)

R-square within

Number of observations

Number of individuals

\begin{tabular}{rr}
.150 & .151 \\
70,949 & 70,949 \\
6,663 & 6,663 \\
\hline
\end{tabular}

.149
63,914
6,024

.149
63,914
6,024

.153
95,016
8,949

$-.622^{* * *}$

$-.620^{* * *}$

(.0506)

(.0507)

Note:

*** significant at the $1 \%$ level

** $\quad$ significant at the $5 \%$ level.

significant at the $10 \%$ level.

All specifications include individual-specific and time-specific fixed effects. Standard errors are given in parentheses. 
Table 5: Total female sample fixed effects regression results of the impact of the AEI relative to LMT, various samples.

Dependent variable: Log annual wage earnings $1991-2003$.

Prior 2-year upp

Municipality with low fraction secondary school of 3-year upp sec diploma

Age 25-42

Age 43-55

AEI total:
1 semester
2 semesters
3 semesters
4 semesters

$$
\begin{aligned}
& -.072^{* * *} \\
& (.0172)
\end{aligned}
$$$$
-.069^{* * *}
$$$$
-.161^{* * *}
$$$$
-.024
$$$$
\text { (.0145) }
$$

$$
\begin{array}{r}
-.017 \\
(.0274)
\end{array}
$$$$
-.048^{*}
$$$$
-.100^{* * *}
$$$$
(.0195)
$$$$
.039^{*}
$$$$
\text { (.0225) }
$$$$
-.119^{* * *}
$$$$
\text { (.0203) }
$$

Age squared

Registered in program

$$
\begin{array}{ll}
-.001^{* * *} & -.001^{* * *} \\
(.0001)^{* * *} & (.0001)^{* * *} \\
-.682^{* *} & -.683^{* * *} \\
(.0249) & (.0250)
\end{array}
$$$$
\begin{gathered}
-.122^{*} \\
(.0194)
\end{gathered}
$$$$
.070^{* * *}
$$$$
\text { (.0225) }
$$$$
-.118^{* * *}
$$$$
\text { (.0203) }
$$

$$
\begin{aligned}
& -.001^{* * *} \\
& (.0001)^{* * *} \\
& -. .707^{* *} \\
& (.0254)
\end{aligned}
$$$$
-.001^{* * *}
$$$$
(.0001)
$$$$
-.706^{* * *}
$$$$
\text { (.0254) }
$$$$
\text { (.0001) }
$$$$
\begin{aligned}
& -.794^{* * *} \\
& -.0219)
\end{aligned}
$$$$
\text { (.0219) }
$$$$
-.102^{* * *}
$$$$
\text { (.0232) }
$$$$
-.208^{* * *}
$$$$
\text { (.0169) }
$$

\begin{tabular}{|c|c|c|c|c|c|c|c|c|}
\hline R-square within & .108 & .108 & .110 & .111 & .108 & .108 & .120 & .120 \\
\hline Number of observations & 141,543 & 141,543 & 131,911 & 131,911 & 176,846 & 176,846 & 51,017 & 51,017 \\
\hline Number of individuals & 12,830 & 12,830 & 12,018 & 12,018 & 16,276 & 16,276 & 4,632 & 4,632 \\
\hline
\end{tabular}$$
-.050^{* *}
$$$$
\text { (.0199) }
$$$$
-.201^{* * *}
$$$$
\text { (.0177) }
$$$$
\text { (.0217) }
$$

(.0364)

$-.004$

(.0267)

$$
.112^{* * *}
$$

$-.133^{* * *}$

$(.0300)$

Note: $\quad{ }^{* * *}$ significant at the $1 \%$ level

** $\quad$ significant at the $5 \%$ level.

significant at the $10 \%$ level.

All specifications include individual-specific and time-specific fixed effects. Standard errors are given in parentheses. 
Table 6: Restricted male sample fixed effects regression results of the impact of the AEI relative to LMT, various samples where participants in education from 2001 and onwards are excluded.

Dependent variable: Log annual wage earnings 1991 - 2003.

Prior 2-year upper

secondary school
Municipality with low fraction of 3-year upp sec diploma Age 25-42

$$
\begin{aligned}
& -.281^{* * *} \\
& (.0171)
\end{aligned}
$$$$
\begin{array}{r}
-.166 \\
(.0197)
\end{array}
$$

1 semester

2 semesters

3 semesters

4 semesters

Age squared

Registered in program

$$
\begin{array}{ll}
-.002^{* * *} & -.002^{* * *} \\
(.0001)^{* *} & (.0001)^{* * *} \\
-.779^{* * *} & -.780^{* *} \\
(.0348) & (.0348)
\end{array}
$$$$
-.140^{* * *}
$$$$
\text { (.0364) }
$$$$
-.180^{* * *}
$$$$
\text { (.0243) }
$$$$
-.108^{* * *}
$$$$
\text { (.0336) }
$$$$
-.199^{* * *}
$$$$
\text { (.0298) }
$$

$$
\begin{gathered}
-.182^{* *} \\
(.0208)
\end{gathered}
$$$$
-.209^{* * *}
$$$$
\text { (.0417) }
$$$$
-.196^{* * *}
$$$$
\text { (.0260) }
$$$$
-.090^{* *}
$$$$
\text { (.0392) }
$$$$
-.198^{* * *}
$$$$
\text { (.0317) }
$$

$-.002^{* * *}$
$(.0001)^{* * *}$
$-.733^{* *}$
$(.0367)$

$-.002^{* * *}$

$$
(.0001)
$$$$
\begin{gathered}
-.733^{* * *} \\
(.0367)
\end{gathered}
$$$$
\text { (.0367) }
$$

\begin{tabular}{rr}
.191 & .191 \\
55,801 & 55,801 \\
5,167 & 5,167 \\
\hline
\end{tabular}

.186
50,687

50,687

4,704

$\begin{array}{r}.186 \\ 50,687 \\ 4,704 \\ \hline\end{array}$

.198
73,573
6,828

$-.003^{* * *}$

$(.0001)$

$-.869^{* * *}$
$(.0304)$

Number of individuals

6,828

significant at the $1 \%$ level

* significant at the $5 \%$ level. significant at the $10 \%$ level.

All specifications include individual-specific and time-specific fixed effects. Standard errors are given in parentheses.

Age 43-55

$$
\begin{array}{r}
-.026 \\
(.0300)
\end{array}
$$

$$
\begin{gathered}
-.359^{* * *} \\
(.0328)^{* * *} \\
-.284^{* * *} \\
(.0215)^{* *} \\
-.199^{* * *} \\
(.0304)^{* *} \\
-.284^{* * *} \\
(.0269)
\end{gathered}
$$

$\begin{array}{lll}-.003^{* * *} & -.003^{* * *} & -.003^{* * *} \\ (.0001)^{* * *} & (.0002)^{* *} & (.0002)^{* * *} \\ -.874^{* *} & -.599^{* * *} & -.599^{* *} \\ (.0305) & (.0527) & (.0528)\end{array}$

\begin{tabular}{rrr}
.198 & .158 & .158 \\
73,573 & 25,509 & 25,509 \\
6,828 & 2,441 & 2,441 \\
\hline
\end{tabular}

Note: 
Table 7: Restricted female sample fixed effects regression results of the impact of the AEI relative to LMT, various samples where participants in education from 2001 and onwards are excluded.

Dependent variable: Log annual wage earnings 1991 - 2003.

Prior 2-year upper

secondary school
Municipality with low fraction of 3-year upp sec diploma Age 25-42

$$
-.091^{* * *}
$$$$
\begin{array}{r}
-.019 \\
(.0187)
\end{array}
$$$$
\begin{array}{r}
-.020 \\
(.0189)
\end{array}
$$$$
-.032
$$$$
\text { (.0268) }
$$

1 semester

2 semesters

3 semesters

4 semesters

$$
\left.\left.{ }^{-.072}\right)^{* 0204 *}\right)_{* *}
$$$$
.060^{* *}
$$$$
\text { (.0236) }
$$

.004

(.0213)

Age squared

Registered in program

$$
\begin{gathered}
-.001^{* * *} \\
(.0001)^{* * *} \\
-.662^{* *} \\
(.0281)
\end{gathered}
$$$$
-.001^{* * *}
$$$$
\text { (.0001) }
$$$$
-.661^{* * *}
$$

$(.0308)$

$$
-.078^{* * *}
$$$$
\text { (.0218) }
$$$$
.076^{* * *}
$$$$
(.0250)
$$$$
\text { - .026 }
$$$$
\text { (.0232) }
$$

(.0282)

$-.001^{* * *}$
$(.0001)^{* * *}$
$-.685^{* *}$
$(.0289)$

$-.001^{* * *}$

$$
(.0001)
$$$$
-.685^{* * *}
$$

-.685
$(.0289)$

-.000
$(.0001)^{* * *}$
$-.776^{* *}$
$(.0254)$

$$
(.0001)^{* * *}
$$$$
-.773^{* * *}
$$

-.773
$(.0255)$

Age 43-55

\begin{tabular}{lrrrrrrr} 
R-square within & .146 & .147 & .151 & .152 & .153 & .154 & .136 \\
Number of observations & 99,760 & 99,760 & 91,749 & 91,749 & 118,859 & 118,859 & 41,867 \\
Number of individuals & 8,931 & 8,931 & 8,243 & 8,243 & 10,792 \\
\hline
\end{tabular}

Note:

significant at the $1 \%$ level

significant at the $5 \%$ level. significant at the $10 \%$ level.

All specifications include individual-specific and time-specific fixed effects. Standard errors are given in parentheses. 
Now, one may wonder about the costs associated with the respective programs. According to the Swedish National Agency for Education, the educational costs of the AEI were SEK 34,000 per year. Assuming then the costs per semester to be SEK 17,000, the fractions that studied 1,2, 3 and 4 semesters can be multiplied by their incurred costs. This would imply average costs of SEK 45,700. The educational costs of LMT, counted as an average per year, were SEK 85,000 (AMS). The mean program length was 171 days, implying an average cost of SEK 40,000. Accordingly, the educational costs of the AEI were SEK 5,700 higher than LMT.

The foregone earnings were higher for the AEI as program duration was longer. The length of a semester is in official documents generalised to 18 weeks $(=126$ days) and the mean program length of the AEI would then be 339 days which is 168 days longer than the mean LMT program time. Estimates of foregone earnings suggest an opportunity cost in the region of SEK 30,000, which then implies that the extra costs incurred via the AEI compared with LMT would be in the region of SEK 35,000 ( $€ 3,800)$. Note that the group which was most expensive, those who remained in the AEI for four semesters, also showed relatively weak pay-off in terms of increased annual wage earnings.

\section{Concluding discussion}

This paper uses register data on a large sample of unemployed persons in Sweden aged 25 to 55 to evaluate the effects on annual wage earnings of comprehensive upper secondary education compared with vocational training. The participants in comprehensive education were registered a minimum of one and a maximum of four semesters in the Adult Education Initiative (AEI) which, from the autumn of 1997, generated an unprecedented expansion of heavily subsidized comprehensive adult education. The participants in a traditional vocational program were part of the stock enrolled in Labour Market Training (LMT) on October 15 in 1997.

Fixed effects regressions on annual wage earnings from 1991 to 2003 imply a negative impact of comprehensive education relative to vocational LMT. The findings suggest that vocational training was more efficient as a labour market policy tool and possibly that the AEI should have been scaled down to the advantage of LMT. However, for individuals aged 43-55, there are in general no significant differences found between the programs. Only minor differences are also obtained for females with a prior two-year upper secondary schooling or residing in a municipality associated with a low educational level. These results suggest that 
more careful targeting of participants in adult education could have improved the relative efficiency of the program.

The findings partly run counter to Stenberg (2005) who found unemployment incidence to be lower among participants in the AEI compared with LMT but also unemployment duration to be longer. It is tempting to believe that estimates based on registered annual wage earnings are more reliable, as those "not in unemployment" could be in such dissimilar activities as employment or withdrawn from the labour market.

Rough calculations to compare program costs, including foregone earnings, indicate that the AEI incurred average costs which exceeded LMT by some $€ 3,800$ per enrolee. 


\section{References}

Albrecht, J.W., van den Bergh, G. and Vroman, S.B. (2004). The knowledge lift: The Swedish adult education program that aimed to eliminate low worker skill levels, IFAU Working Paper 2004:17, Uppsala.

AMS (1999). Uppföljning av kursdeltagare som slutat yrkesinriktad arbetsmarknadsutbildning andra kvartalet 1998. Prora 1999:1. AMS.

AMS (2000). Uppföljning av kursdeltagare som slutat yrkesinriktad arbetsmarknadsutbildning andra kvartalet 1999. Prora 2000:1. AMS.

Andrén, T. and Gustafsson, B. (2005). Income Effects from Labour Market Training Programs in Sweden During the 80's and 90's, accepted for publication in International Journal of Manpower.

Axelsson, R. and Westerlund, O. (2005). Kunskapslyftets effekter på årsarbetsinkomster - Nybörjare höstterminen 1997. Umeå Economic Studies 647.

Egerton, M. and Parry, G. (2001). Lifelong debt: rates of return to mature study, Higher Education Quarterly 55, 4-27.

Ekström, E. (2003). Essays on Inequality and Education. Ph.D. dissertation, Economic Studies 76, Uppsala Universitet.

Grubb, N.W. (2002). Learning and earning in the middle, part I: national studies of pre-baccalaureate education, Economics of Education Review 21, 299321.

Harkman, A., Jansson, F. and Tamás, A. (1996). Effects, defects and prospects an evaluation of labour market training in Sweden, AMS Working Paper 1996:5, Solna.

Jacobson, L.S., LaLonde, R.J. and Sullivan, D.G. (2005). The returns to community college schooling for displaced workers, Journal of Econometrics 125, 271-304.

Jenkins, A. (2004). Women, Lifelong Learning and Employment, Working Paper, Centre for the Economics of Education, LSE, London.

Jenkins, A., Vignoles, A. Wolf, A. and Galindo-Rueda, F. (2003). The determinants and labour market effects of lifelong learning, Applied Economics 35, 1711-21.

Larsson, L. (2000). Evaluation of Swedish youth programs, Journal of Human Resources, 38(4), 891-927.

Leigh, D.E. and Gill, A.M. (1997). Labor Market returns to Community Colleges: Evidence for Returning Adults. Journal of Human Resources, 32(2), 334353.

Okeke, S. (2001). Arbetsmarknadsutbildningen 1999 - effekter för individen, Ura 
2001:7, AMS, Stockholm.

Regnér, H. (2002). A nonexperimental evaluation of training programs for the unemployed in Sweden. Labour Economics 9, 187-206.

Richardson, C. and van den Bergh, G. (2002). Swedish labour market training and the duration of unemployment, Swedish Economic Policy Review 8, 175213.

Sianesi, B. (2001). The Swedish active labour market programmes in the 1990s: Overall effectiveness and differential performance, Swedish Economic Policy Review 8, 133-69.

SOU 1998:51. Vuxenutbildning och livslångt lärande. Situationen inför och under första året med Kunskapslyftet. Reports of the Government Commission, Ministry of Education and Science, Stockholm.

SOU 1999:39. Vuxenutbildning för alla? Andra året med Kunskapslyftet. Reports of the Government Commissions, Ministry of Education and Science, Stockholm.

Stenberg, A. (2005). Comprehensive Education for the Unemployed - Evaluating the Effects on Unemployment for the Adult Education Initiative in Sweden. Labour 19(1), 123-146.

Stenberg, A. and Westerlund, O. (2004). Does Comprehensive Education Work for the Unemployed. Umeå Economic Studies 641. 